\title{
Heart Rate Acceleration of a Subsidiary Pacemaker by $\beta$-Adrenergic Stimulation
}

\author{
Sanghoon Park ${ }^{1}$, Hyerim Park ${ }^{1}$, Hye Jin Hwang, MD ${ }^{1}$, Jaemin Shim, MD ${ }^{1}$, Jung-Hoon Sung, MD ${ }^{2}$, \\ Jong-Youn Kim, $\mathrm{MD}^{1}$, Hui-Nam Pak, $\mathrm{MD}^{1}$, Moon-Hyoung Lee, $\mathrm{MD}^{1}$, and Boyoung Joung, $\mathrm{MD}^{1}$ \\ ${ }^{1}$ Division of Cardiology, Department of Internal Medicine, Yonsei University College of Medicine, Seoul, \\ ${ }^{2}$ Division of Cardiology, Department of Internal Medicine, CHA Bundang Medical Center, CHA University, Seongnam, Korea
}

\begin{abstract}
Background and Objectives: Recent evidence indicates that the membrane voltage and $\mathrm{Ca}^{2+}$ clocks jointly regulate sinoatrial node (SAN) automaticity. However, the mechanism of heart rhythm acceleration of the subsidiary pacemaker (SP) during $\beta$-adrenergic stimulation is still unknown. Here we tested the hypothesis that the heart rate acceleration of the SP by $\beta$-adrenergic stimulation involves synergistic interactions between both clock mechanisms. Materials and Methods: We performed optical mapping and pharmacological interventions in 15 isolated Langendorff-perfused canine right atriums (RA). The SP model was produced by ligation of the SAN artery at the mid portion of the sulcus terminalis. Results: In the 6 RAs with an intact SAN, $1 \mu \mathrm{mol} / \mathrm{L}$ isoproterenol infusion increased the heart rate from $82 \pm 9$ to $166 \pm 18 \mathrm{bpm}(102 \%)$ with late diastolic $\mathrm{Ca}_{\mathrm{i}}$ elevation (LDCAE) at the superior SAN. However, in the $6 \mathrm{SP}$ models, the heart rate increased from $55 \pm 10 \mathrm{bpm}$ to $106 \pm 11 \mathrm{bpm}(92 \%, \mathrm{p}=0.005)$ without LDCAE at the earliest activation site. The isoproterenol induced heart rate increase was reversed to $74 \pm 5 \mathrm{bpm}$ ( $33 \%$ from baseline) by administering an infusion of the funny current blocker ZD 7288 ( $3 \mu \mathrm{mol} /$ $\mathrm{L}, \mathrm{n}=3$ ), whereas, it was suppressed to $69 \pm 7 \mathrm{bpm}$ ( $24 \%$ from baseline) by sarcoplasmic reticulum (SR) $\mathrm{Ca}^{2+}$ emptying with administering ryanodine $(10 \mu \mathrm{mol} / \mathrm{L})$ plus thapsigargin $(200 \mathrm{nmol} / \mathrm{L}, \mathrm{n}=3)$. The isoproterenol induced heart rate increase was completely abolished by combined treatment with funny current blocker and $\mathrm{SR} \mathrm{Ca}^{2+}$ emptying $(\mathrm{n}=3)$. Conclusion: Acceleration of the $\mathrm{Ca}^{2+}$ clock in the SP plays an important role in the heart rate acceleration during $\beta$-adrenergic stimulation, and this interacts synergistically with the voltage clock to increase the heart rate. (Korean Circ J 2011;41:658-665)
\end{abstract}

KEY WORDS: Calcium channel; Sympathetic nervous system; Sinoatrial node.

\section{Introduction}

The sinoatrial node (SAN) automaticity is responsible for initiating the heart rhythm. So, the SAN function is essential for normal cardiac physiology. Sick sinus syndrome is an abnormality involving the generation of the action potential by

Received: February 26, 2011

Revision Received: March 11, 2011

Accepted: March 12, 2011

Correspondence: Boyoung Joung, MD, Division of Cardiology, Department of Internal Medicine, Yonsei University College of Medicine, 250 Seongsan-ro, Seodaemun-gu, Seoul 120-752, Korea

Tel: 82-2-2228-8460, Fax: 82-2-393-2041

E-mail: cby6908@yuhs.ac

- The authors have no financial conflicts of interest.

(a) This is an Open Access article distributed under the terms of the Creative Commons Attribution Non-Commercial License (http://creativecommons.org/licenses/by-nc/3.0) which permits unrestricted non-commercial use, distribution, and reproduction in any medium, provided the original work is properly cited. the SAN and this is characterized by an atrial rate that is inappropriate for the physiological requirements. Sick sinus syndrome occurs in 1 of every 600 cardiac patients older than 65 years and it accounts for approximately half of the implantations of pacemakers in the United States. ${ }^{1)}$

The spontaneous firing of a subsidiary pacemaker (SP) is important as the secondary pacemaker in patients with sick sinus syndrome. Randall et al. ${ }^{2)}$ reported that a supraventricular (atrial) rhythm resumed after surgical excision of the SAN in both resting and exercising dogs. Waxing and waning of the heart rate, which is generally referred to as sinus arrhythmia, continues in the awake animal after complete excision of the SAN. This arrhythmia is responsive to both adrenergic and cholinergic interventions, and this indicates the presence of both sympathetic and parasympathetic regulation of the subsidiary atrial pacemaking tissues. ${ }^{2}$ Ligation of the SAN artery at the mid portion of the sulcus terminalis suppressed the SAN activity and elicited SP activity in a well-defined re- 
gion of the inferior atrium. ${ }^{3)}$

Spontaneous diastolic depolarization of the SAN cells periodically initiates action potentials to set the rhythm of the heart. The mechanism of spontaneous diastolic depolarization has traditionally been attributed to a "voltage clock" mechanism that is mediated by voltage-sensitive membrane currents such as the hyperpolarization-activated pacemaker current $\left(\mathrm{I}_{\mathrm{f}}\right)$ regulated by cyclic adenosine mono-phosphate. ${ }^{4) 5}$ The " $\mathrm{Ca}^{2+}$ clock" has recently been proposed as a complimentary mechanism of SAN automaticity. ${ }^{6-14)}$ The $\mathrm{Ca}^{2+}$ clock is mediated by rhythmic spontaneous sarcoplasmic reticulum (SR) $\mathrm{Ca}^{2+}$ release, which in turn activates the $\mathrm{Na}^{+} / \mathrm{Ca}^{2+}$ exchanger current (INCX) and causes diastolic depolarization. ${ }^{(8)-1115)}$ However, the mechanism of spontaneous firing of the SP has not been revealed. It is also unclear how the heart rate accelerates after sympathetic stimulation of the SP. The purpose of the present study was to make various pacemaker models and reveal the mechanism of spontaneous firing and heart rate acceleration by sympathetic stimulation of the SP.

\section{Materials and Methods}

\section{Various Langendorff-perfused canine right atrium preparations}

This study's protocol was approved by the Institutional Animal Care and Use Committee and it conforms to the guidelines of the American Heart Association. We studied the isolated canine right atriums (RA) from 15 mongrel dogs (22 to $28 \mathrm{~kg}$ ). The dogs were intubated and anesthetized with isoflurane. The chest was opened via a median sternotomy and the heart was rapidly excised. The dogs were euthanized by exsanguination during general anesthesia. The right coronary artery was perfused with $37^{\circ} \mathrm{C}$ Tyrode's solution equilibrated with $95 \% \mathrm{O}_{2}$ and $5 \% \mathrm{CO}_{2}$ to maintain a $\mathrm{pH}$ of 7.4. The composition of Tyrode's solution was (in mmol/L): $125 \mathrm{NaCl}, 4.5$ $\mathrm{KCl}, 0.25 \mathrm{MgCl}_{2}, 24 \mathrm{NaHCO}_{3}, 1.8 \mathrm{NaH}_{2} \mathrm{PO}_{4}, 1.8 \mathrm{CaCl}_{2}$ and 5.5 glucose. The perfusion pressure was between $50 \mathrm{~mm} \mathrm{Hg}$ and $60 \mathrm{~mm} \mathrm{Hg}$. All the ventricular coronary branches were tied off. Both ventricles and the left atrium were excised and removed from the preparation. During the optical recordings, contractility was inhibited by $10-17 \mu \mathrm{mol} / \mathrm{L}$ of blebbistatin. ${ }^{12)}$

We produced various RA perfusion models by isoproterenol infusion and ligation of the SAN artery. The superior RA model was produced by isoproterenol infusion of $1 \mu \mathrm{mol} / \mathrm{L}$. The middle and inferior SAN models were produced by the ligation of the sulcus terminalis at the upper sixth portion and the upper third portion. Finally, the SP model was generated by ligating the mid portion of the sulcus terminalis (Fig. 1). The time interval between the each ligation was 20 minutes.

\section{Dual $\mathrm{V}_{\mathrm{m}}$ and $\mathrm{Ca}_{\mathrm{i}}$ recordings}

Dual $\mathrm{V}_{\mathrm{m}}$ and $\mathrm{Ca}_{\mathrm{i}}$ recording was performed in 9 dogs. We used $0.5 \mathrm{mg}$ of Rhod-2 AM (Molecular Probes) dissolved in $1 \mathrm{~mL}$ of dimethylsulfoxide containing Pluronic F-127 (20\%wt/ vol) to stain the $\mathrm{Ca}_{\mathrm{i}}$. This solution was diluted in $300 \mathrm{~mL}$ of Tyrode's solution to achieve a final Rhod-2 concentration of $1.48 \mu \mathrm{mol} / \mathrm{L}$ and this was infused into the heart over a $10 \mathrm{mi}-$ nutes period. The heart was perfused with dye-free Tyrode's solution for 15-30 minutes for de-esterification of Rhod-2 $\mathrm{AM}$. The hearts were then stained again by direct injection of voltage sensitive dye (RH237, Molecular Probes) into the perfusion system. ${ }^{12)}$ The double-stained hearts were excited with two LED lamps at $532 \mathrm{~nm}$. The fluorescence was collected using a 2 image-intensified charge-coupled device (CCD) camera (Dalsa Inc., Waterloo, Canada) at $3.75 \mathrm{~ms} /$ frame and $125 \times 125$ pixels with spatial resolution of $0.24 \times 0.24 \mathrm{~mm}^{2} /$ pixel. ${ }^{16)}$ The CCD camera for the $V_{m}$ was fitted with a $715-\mathrm{nm}$ long-pass filter, and the CCD camera for the $\mathrm{Ca}_{\mathrm{i}}$ was fitted with a $580 \pm 20$-nm band-pass filter. After dual $\mathrm{V}_{\mathrm{m}}$ and $\mathrm{Ca}_{\mathrm{i}}$ optical mapping of the baseline spontaneous beats, isoproterenol was infused starting from $0.01 \mu \mathrm{mol} / \mathrm{L}$ and this was gradually increased to $1.0 \mu \mathrm{mol} / \mathrm{L}$. The isoproterenol dose responses were evaluated in 6 RAs with intact SANs and 3 SP models. Because late diastolic $\mathrm{Ca}_{\mathrm{i}}$ elevation (LDCAE) was not observed in all $3 \mathrm{SP}$ models, $\mathrm{V}_{\mathrm{m}}$ recordings were performed in 6 additional SP models using di-4-ANEPPS (Invitrogen, California, USA). The pharmacologic interventions were as follows: $Z \mathrm{DD} 7288(3 \mu \mathrm{mol} / \mathrm{L}, \mathrm{n}=2)$, ryanodine $(3 \mu \mathrm{mol} / \mathrm{L}, \mathrm{n}=2)$, isoproterenol $(1 \mu \mathrm{mol} / \mathrm{L}, \mathrm{n}=6)$ and then this was followed by $\mathrm{ZD} 7288(3 \mu \mathrm{mol} / \mathrm{L}, \mathrm{n}=3)$, ryanodine $(3 \mu \mathrm{mol} / \mathrm{L}, \mathrm{n}=2)$ and $\mathrm{ry}-$ anodine $(10 \mu \mathrm{mol} / \mathrm{L})$ plus thapsigargin $(200 \mathrm{nmol} / \mathrm{L})(\mathrm{n}=3)$. Finally, to block both the $\mathrm{Ca}^{2+}$ and voltage clocks, a combin-
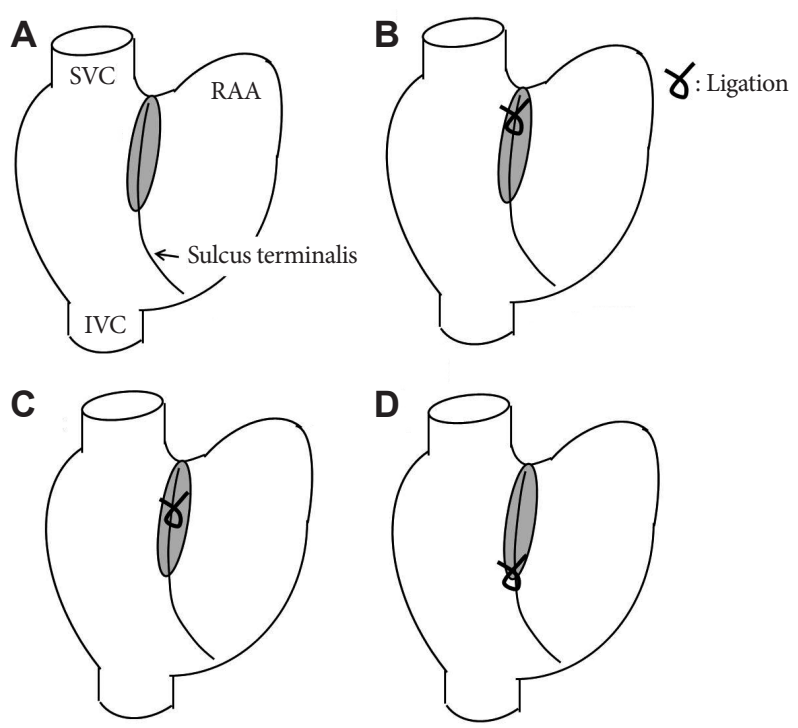

Fig. 1. The various pacemaker models. $A$ : intact $R A$ and superior $S A N$ model. B: middle SAN model. C: inferior SAN model. D: subsidiary pacemaker model. The subsidiary pacemaker model was produced by the ligation of the SAN artery. SAN: sinoatrial node, RA: right atrium, SVC: superior rena cava, IVC: inferior vena cava, RAA: right atrium appendage. 
ed infusion of ryanodine $(10 \mu \mathrm{mol} / \mathrm{L})$, thapsigargin $(200 \mathrm{nmol} /$ $\mathrm{L})$ and ZD $7288(3 \mu \mathrm{mol} / \mathrm{L})$ was performed in 3 SP models.

\section{Data analysis}

The $\mathrm{Ca}_{\mathrm{i}}$ and $\mathrm{V}_{\mathrm{m}}$ traces were normalized to their respective peak-to-peak amplitude for comparison of the timing and the morphology. We generated activation isochronal maps using the onset of the phase 0 of the action potential in the leading pacemaker site as time 0 . The time of the isochronal map is the time when the $\mathrm{dV}_{\mathrm{m}} / \mathrm{dt}$ reached the peak amplitude of phase 0 . Student's t-tests were used to compare means between the two groups. A p $<0.05$ was considered significant.

\section{Results}

The effects of sequential ligation of the sinoatrial node artery on the heart rate and the pacemaking site

The SAN artery was ligated sequentially at the superior to middle portion of the sulcus terminalis. Fig. 2 shows the differential responses of the different SAN models to isoproterenol infusion. At baseline, the mean heart rate was $90 \pm 23 \mathrm{bpm}$, and the middle part of the SAN served as the pacemaking site (site 1 of Fig. $2 \mathrm{~A}$ ). After infusing $\mu \mathrm{mol} / \mathrm{L}$ of isoproterenol, the heart rate was increased to $189 \pm 11 \mathrm{bpm}$ and the leading pacemaking site was shifted cranially and this produced the superior SAN model (site 2 of Fig. 2A). After ligation of the SAN at the superior sixth portion of the sulcus terminalis, the heart rate was decreased to $151 \pm 28 \mathrm{bpm}$ and this produced the middle SAN model. The heart rate was $128 \pm 26$ and $106 \pm 11 \mathrm{bpm}$ in the inferior and SP models, respectively (Fig. 2B).

\section{Impaired heart rate response to $\beta$-adrenergic stimulation in the subsidiary pacemaker model}

Fig. 3 shows the isoproterenol-dose response curve of the heart rate obtained from 6 RAs with an intact SAN and 3 SP models. The baseline heart rate of the SP models was $55 \pm 10$ bpm, and this was significantly lower than that of the RAs with an intact SAN (90 $\pm 23 \mathrm{bpm}, \mathrm{p}=0.004)$. In the RAs with an intact SAN, an isoproterenol dosage of $1 \mu \mathrm{mol} / \mathrm{L}$ increased the heart rate to $166 \pm 18 \mathrm{bpm}(102 \%)$. In contrast, the heart rate of the SP models increased only to $97 \pm 35 \mathrm{bpm}(73 \%, \mathrm{p}=$ 0.005) during isoproterenol infusion. Compared with the RAs with an intact SAN, the isoproterenol heart rate response cur-

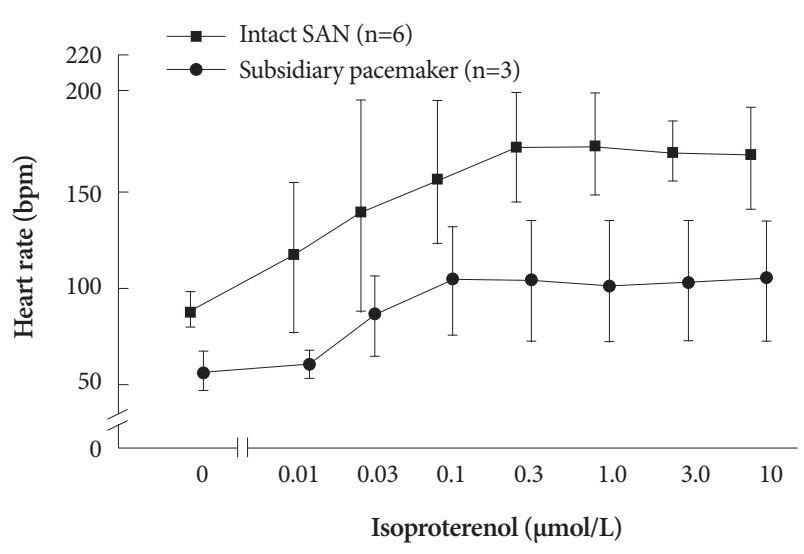

Fig. 3. Impaired isoproterenol-induced heart rate increase in the subsidiary pacemaker model. We tested the isoproterenol dose response curve in 6 RAs with an intact SAN and 3 subsidiary pacemaker models. Compared to the RAs with an intact SAN (square), the subsidiary pacemaker model (circle) showed a significantly impaired heart rate increase during isoproterenol infusion. SAN: sinoatrial node, RA: right atrium.

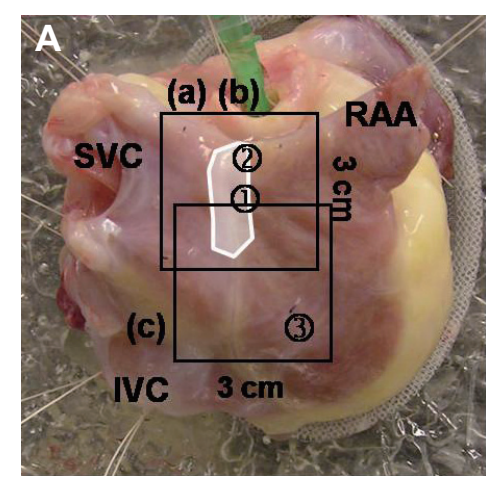

(a) RA

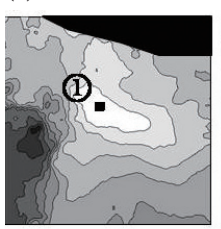

(b) Sup

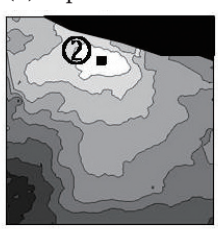

(c) Sub

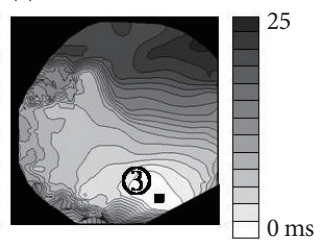

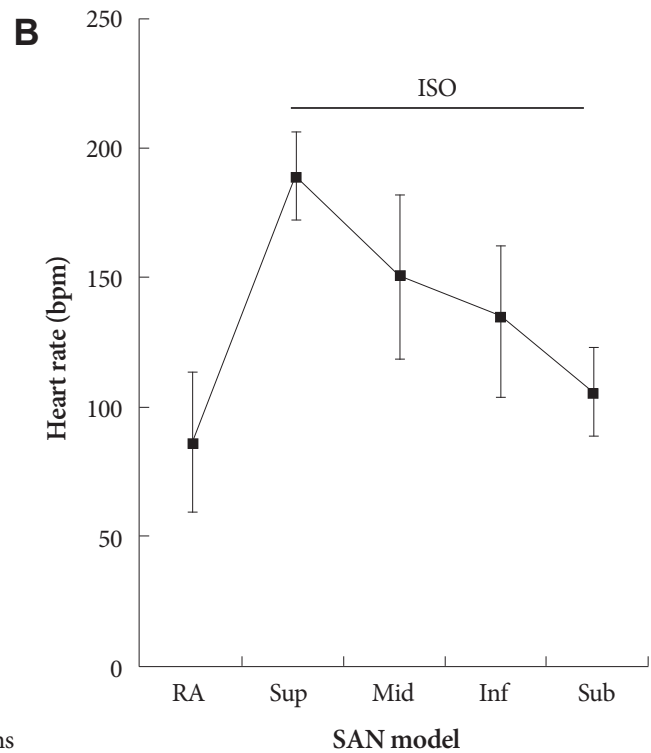

Fig. 2. The effects of sequential ligation of the SAN artery on the heart rate and the leading pacemaking sites. A, Upper panel: epicardial photographs of a perfused right atrial preparation with $3 \times 3 \mathrm{~cm}$ optical fields of view. The upper and lower boxes present the optical fields of Fig. a-b and c, respectively. Lower panels: $V_{m}$ isochronal maps of the RA (a), the superior SAN (b) and the subsidiary pacemaker model (c). B: heart rate changes of the various pacemaker models. The white shaded area is the SAN. SVC: superior rena cava, RAA: right atrium appendage, IVC: inferior vena cava, ISO: isoproterenol, RA: right atrium, Sup: superior, Sub: subsidiary pacemaker, inf: inferior, SAN: sinoatrial node. 
ve of the SP model was shifted rightward. This finding suggests impaired heart rate acceleration at the each dosage of isoproterenol.
The $\mathrm{Ca}_{\mathrm{i}}$ dynamics of the subsidiary pacemaker site after $\beta$-adrenergic stimulation

The superior SAN model was produced by infusion of 1 $\mu \mathrm{mol} / \mathrm{L}$ isoproterenol in the RAs with an intact SAN. Fig. $4 \mathrm{Ba}$
A

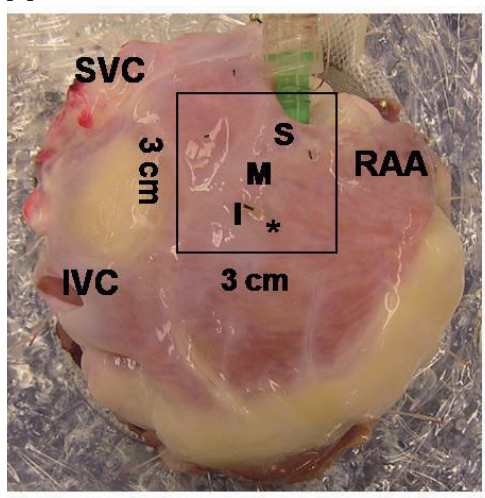

B

(a) Baseline
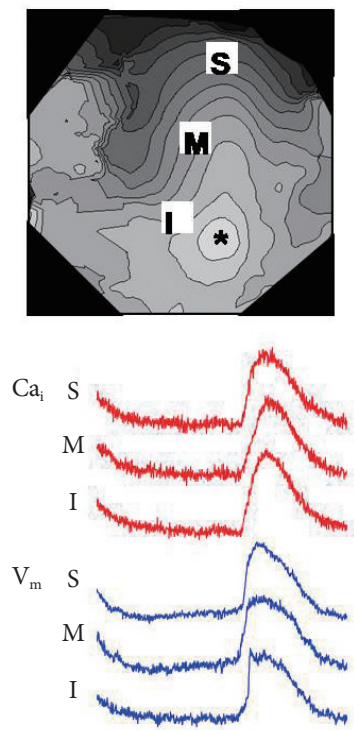

(b) Isoproterenol
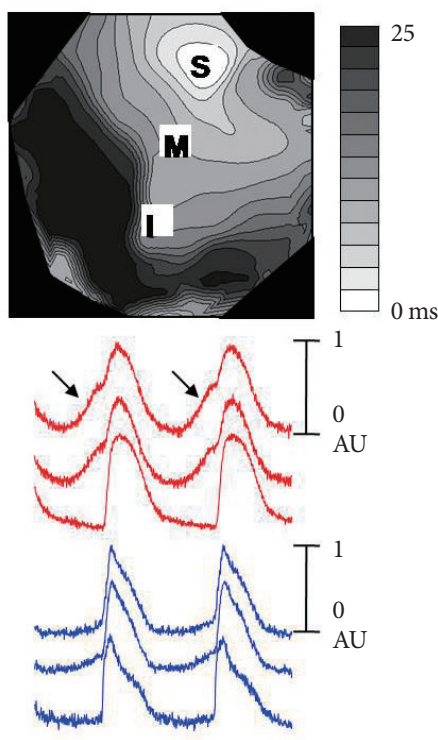

$\overline{200 \mathrm{~ms}}$

Fig. 4. Isoproterenol response of the Langendorff-perfused RAs with an intact SAN. A: epicardial photographs of a perfused RA preparation with $3 \times 3 \mathrm{~cm}$ optical fields of view. B: (a) baseline with a sinus rate of $94 \mathrm{bpm}$. (b) isoproterenol infusion of $1 \mu \mathrm{mol} / \mathrm{L}$ with a sinus rate of $160 \mathrm{bpm}$. Upper panels, RA $V_{m}$ isochronal map. Lower panels, $C_{a i}$ and $V_{m}$ tracings from the superior $(S)$, mid $(M)$ and inferior (I) SANs. Note the heart rate increase and shifting of the leading pacemaker site to the superior SAN with robust LDCAE (arrows). The earliest activation of the RA was considered as 0 ms. IVC: inferior vena cava, RAA: RA appendage, SVC: superior vena cava.

A

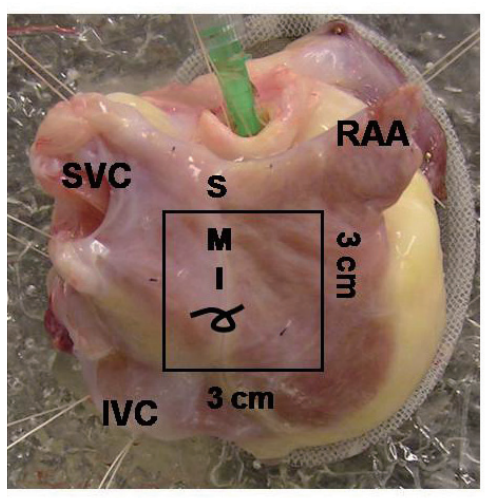

$\widetilde{0}$ : ligation
B

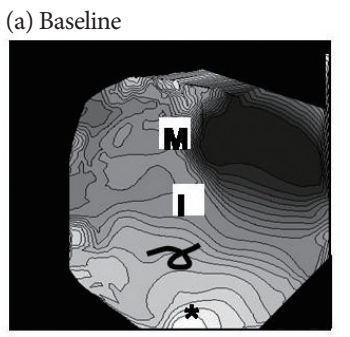

(b) Isoproterenol

$\mathrm{Ca}_{\mathrm{i}}$
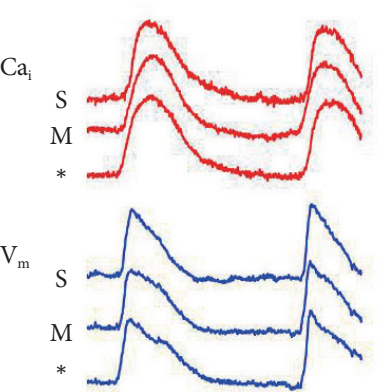
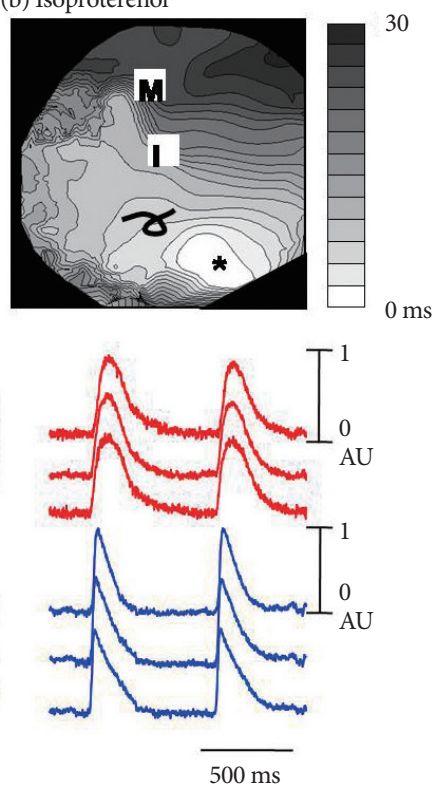

Fig. 5. Complete absence of LDCAE in the subsidiary PM model during isoproterenol infusion. A: epicardial photographs of a perfused right atrial preparation with $3 \times 3 \mathrm{~cm}$ optical fields of view. $B$ : the $R A V_{m}$ isochronal map (upper panels) and the $C a_{i}$ and $V_{m}$ tracings (lower panels) at baseline (a) and at the time of isoproterenol infusion (b). (a) Baseline with a heart rate of $60 \mathrm{bpm}$. (b) Isoproterenol infusion of $1 \mu \mathrm{mol} / \mathrm{L}$ with a sinus rate of 100 bpm. $\mathrm{Ca}_{i}$ and $\mathrm{V}_{\mathrm{m}}$ tracings were recorded from the superior $(\mathrm{S})$ and mid $(\mathrm{M}) \mathrm{SANs}$, and the earliest activation site of the subsidiary pacemaker $(*)$. The stable subsidiary pacemaker was generated by ligation of the SAN artery. However, LDCAE was not observed at the earliest activation site of the subsidiary pacemaker. The earliest activation of RA was considered as 0 ms. IVC: inferior vena cava, RAA: RA appendage, SVC: superior vena cava, LDCAE: late diastolic Cai elevation, PM: paumaker, SAN: sinoatrial node. 
shows the activation map during spontaneous sinus rhythm. The earliest activation site was in the anteroinferior region of the SAN (asterisk). Isoproterenol infusion resulted in an upward (cranial) shift of the earliest activation site to the superior SAN (site s, Fig. 4A), and this was coincident with the appearance of robust LDCAEs (arrows in Fig. 4B) in this region in all 6 preparations.

However, LDCAEs were not observed in the SP model. Fig. $5 \mathrm{Ba}$ shows the activation map during spontaneous rhythm in a SP model. The earliest activation site was located below the ligation site at the inferior portion of the sulcus terminalis. Fig. $5 \mathrm{Bb}$ shows the activation map during $1 \mu \mathrm{mol} / \mathrm{L}$ infusion of isoproterenol infusion. The heart rate increased from $60 \mathrm{bpm}$ to $100 \mathrm{bpm}$, and the activation site was slighted moved to an anterior adjacent site. However, the $\mathrm{Ca}_{\mathrm{i}}$ tracing showed no LD$\mathrm{CAE}$ anywhere in the mapped region (Fig. $5 \mathrm{Bb}$ ). In addition, the LDCAE was not observed with different dosages of isoproterenol from 0.01 to $10 \mu \mathrm{mol} / \mathrm{L}$. The ligation of the SAN artery transiently induced an irregular heart beat (Fig. 6B). However, the heart rhythm was stabilized usually 10 minutes after ligation of the SNA artery (Fig. 6C). The activation maps are presented in Fig. 6E.
The effects of sarcoplasmic reticulum inhibition and if blockade on the heart rate and its acceleration by isoproterenol

We could not find the LDCAE in the SP model at baseline and even during isoproterenol infusion. In the state without isoproterenol pretreatment, ryanodine infusion $3 \mu \mathrm{mol} / \mathrm{L}$ decreased the heart rate of the SP from $55 \pm 10 \mathrm{bpm}$ to $52 \pm 5 \mathrm{bpm}$ (-7\% from baseline).

Fig. $6 \mathrm{D}$ and $\mathrm{F}$ show the $\mathrm{V}_{\mathrm{m}}$ tracing and activation map after ryanodine infusion in the state with isoproterenol pretreatment. The leading pacemaker site was shifted from the anterior RA (site b) to the IVC (site c) after ryanodine infusion. Ryanodine also decreased the isoproterenol-induced heart rate increase of the SP from $106 \pm 11 \mathrm{bpm}$ ( $92 \%$ from baseline) to $83 \pm 3 \mathrm{bpm}$ (50\% from baseline) (Fig. 7) in 2 SP models. To fully suppress the SR Ca ${ }^{2+}$ cycling, we also studied the effects of ryanodine $(10 \mu \mathrm{mol} / \mathrm{L})$ in combination with thapsigargin $(200$ $\mathrm{nmol} / \mathrm{L})$. After 30 minutes treatment, the mean heart rate further decreased to $69 \pm 7 \mathrm{bpm}$ (24\% from baseline, $\mathrm{n}=3$ ).

In contrast to the SR inhibitors, the $\mathrm{I}_{\mathrm{f}}$ blocker ZD $7288(3$ $\mu \mathrm{mol} / \mathrm{L})$ decreased the basal heart rate to $44 \pm 5 \mathrm{bpm}(-21 \%$, $\mathrm{n}=2$ ), and it also partially prevented isoproterenol from increasing the heart rate to $74 \pm 5 \mathrm{bpm}(33 \%$ from baseline, $\mathrm{n}=3$ )
A

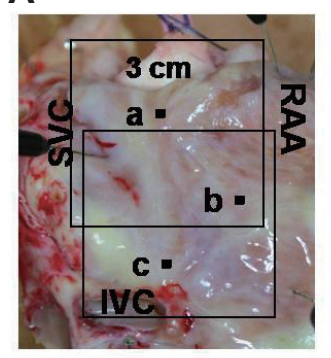

C

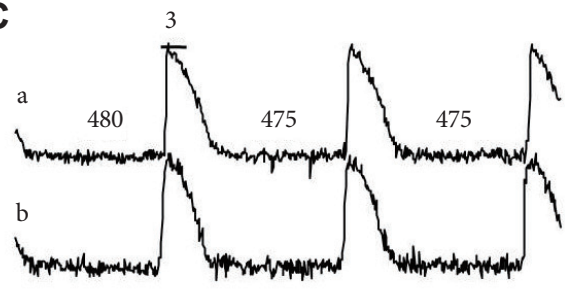

E

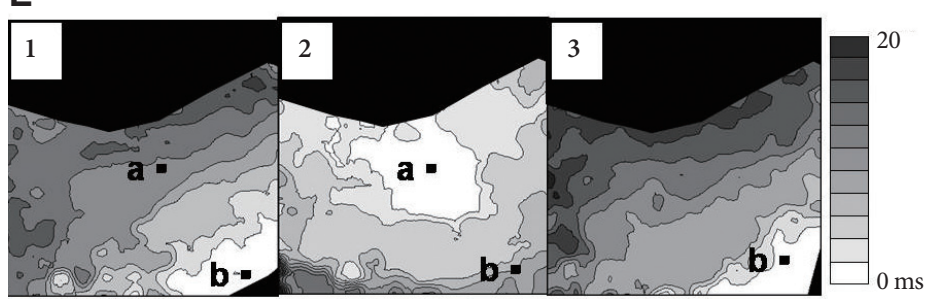

B

D
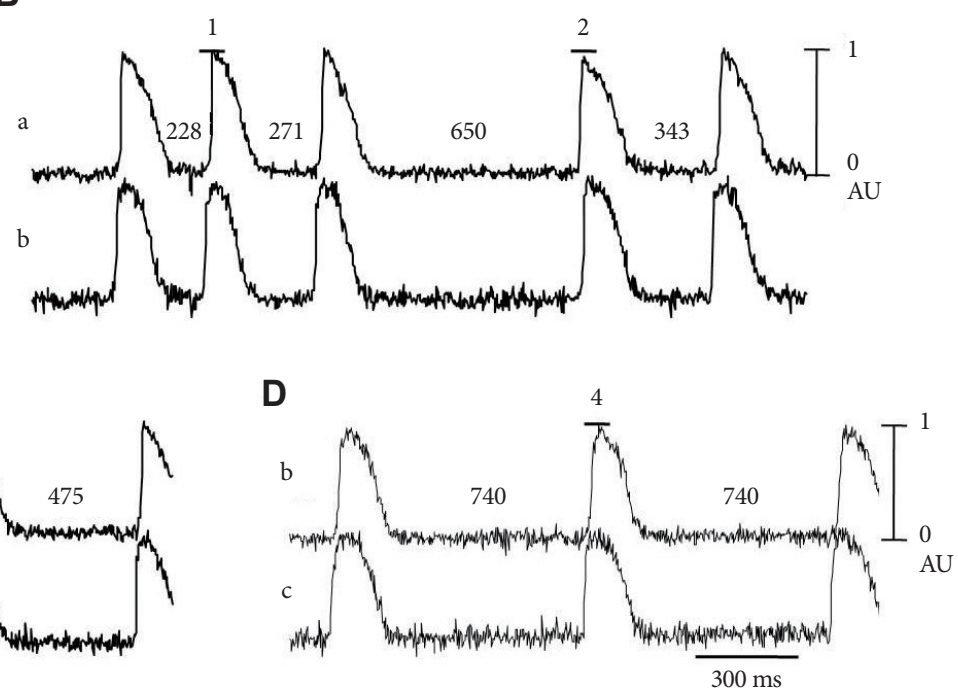

$\mathbf{F}$

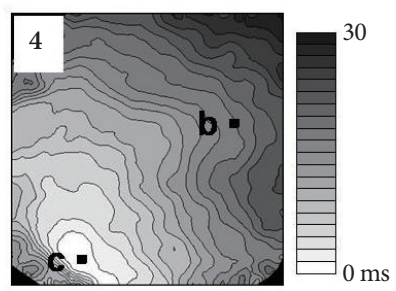

Fig. 6. Transient irregular rhythm after ligation of the superior part of the SAN artery. A: epicardial photographs of a perfused right atrial preparation with $3 \times 3 \mathrm{~cm}$ optical fields of view. The upper and lower boxes present the optical fields of Fig. $E$ and $F$, respectively. B and $C, V_{m}$ tracings from the RA anterior (a) and superior CT (b) marked in Fig. E. B, Transient irregular rhythm immediately after SAN artery ligation. C: stable rhythm 10 minutes after SAN artery ligation. D: ryanodine infusion of $3 \mu \mathrm{mol} / \mathrm{L}$. E: activation maps of the beats 1 and 2 (Fig. 6B) and 3 (Fig. 6C). F: shifting of the subsidiary pacemaker site to the inferior $C T$. The numbers on the $V_{m}$ tracings of Fig. $B$ to $D$ present the beats from which the activation map was generated. IVC: inferior vena cava, RAA: RA appendage, SVC: superior vena cava. 


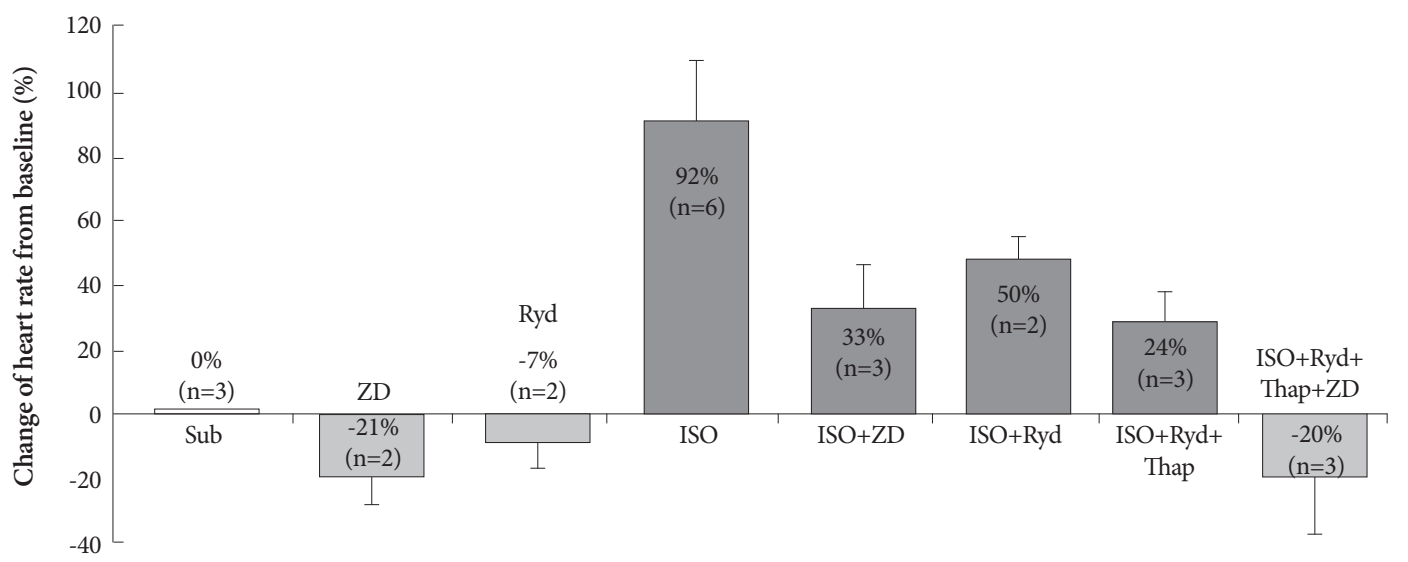

Fig. 7. Spontaneous heart rate of the subsidiary pacemaker depends upon both $\mathrm{Ca}^{2+}$-related mechanisms and the $\mathrm{I}_{\mathrm{f}}$ current. The bars show a change in heart rate (\% from baseline) induced by different pharmacological interventions. The black bars show the changes during $3 \mu \mathrm{mol} / \mathrm{L}$ ZD $7288,3 \mu \mathrm{mol} / \mathrm{L}$ ryanodine, $10 \mu \mathrm{mol} / \mathrm{L}$ ryanodine plus $200 \mathrm{nmol} / \mathrm{L}$ thapsigargin infusion and $10 \mu \mathrm{mol} / \mathrm{L}$ ryanodine plus $200 \mathrm{nmol} / \mathrm{L}$ thapsigargin plus 3 $\mu \mathrm{mol} / \mathrm{L}$ ZD 7288 infusion with $1 \mu \mathrm{mol} / \mathrm{L}$ ISO infusion. The grey bars show the changes during $3 \mu \mathrm{mol} / \mathrm{L}$ ZD 7288 and $3 \mu \mathrm{mol} / \mathrm{L}$ ryanodine without an ISO infusion. ISO: isoproterenol.

\section{(Fig. 7).}

If the voltage and $\mathrm{Ca}_{\mathrm{i}}$ clocks act interdependently and synergistically to support each other in determining the SP rate, then the effects of blocking one clock or the other are likely to be complex and not necessarily very informative. This was the case, as shown in Fig. 7, which summarizes the relative changes in heart rate caused by various pharmacologic agents under basal conditions and during isoproterenol infusion. In addition, the isoproterenol-induced heart rate increase was completely abolished by combined funny current blocker and SR $\mathrm{Ca}^{2+}$ emptying. The combined infusion of ryanodine $(10 \mu \mathrm{mol} /$ $\mathrm{L})$, thapsigargin $(200 \mathrm{nmol} / \mathrm{L})$ and $\mathrm{ZD} 7288(3 \mu \mathrm{mol} / \mathrm{L})$ further decreased the heart rate to $44 \pm 10 \mathrm{bpm}$ ( $-20 \%$ from baseline, $n=3$ ) (Fig. 7).

\section{Discussion}

\section{Major findings}

The present study supports the importance of the $\mathrm{I}_{\mathrm{f}}$ current and spontaneous $\mathrm{SR} \mathrm{Ca}^{2+}$ release to the pacemaking of the SP. The key findings include the demonstration of various pacemaker models with different pacemaking sites and heart rates. The block of spontaneous SR Ca ${ }^{2+}$ release decreased the firing rate of the SP, and this showed the concomitant suppression of heart rate acceleration by $\beta$-adrenergic stimulation. The baseline heart rate and heart rate acceleration by $\beta$-adrenergic stimulation was partially blocked by ZD 7288 , which is a specific If current inhibitor. In addition, we have demonstrated that the isoproterenol-induced heart rate acceleration was completely abolished by blocking both the $\mathrm{I}_{\mathrm{f}}$ current and the spontaneous $\mathrm{SR} \mathrm{Ca}^{2+}$ release. Together, these findings support the conclusion that spontaneous $\mathrm{SR} \mathrm{Ca}^{2+}$ release acts synergistically with the activation of membrane ionic currents such as $I_{f}$, to accelerate the heart rate in a SP model during $\beta$-adrenergic stimulation.

\section{Subsidiary pacemaker models}

Rozanski et al. ${ }^{3)}$ suggested that ligation of the SAN artery at the mid portion of the sulcus terminalis suppressed SAN activity and it usually (73.5\%) elicited ectopic atrial rhythm activity in a well-defined region of the inferior atrium. In this study, we sequentially ligated the SAN artery from the upper part to the mid portion of the sulcus terminalis, and we confirmed the decrease of heart rate and shifting of the leading pacemaker sites. The pacemaker site was well correlated with the heart rate. In this study, after the ligation of the SAN artery at the upper sixth of the sulcus terminalis, the heart rate was not increased to the level of the superior SAN model and the leading pacemaker site was the middle part of the SAN. Fedorov et al. ${ }^{17)}$ suggested that the canine SAN is insulated from the surrounding atrial myocardium except for 2 narrow superior and inferior sinoatrial exit pathways. In this case, the superior exit was blocked first because we ligated the SAN artery from the superior portion of the sulcus terminalis. However, sequential ligation of the SAN artery always decreased the heart rate. Therefore, our study suggests that the pacemaker hierarchy is the shifting of the leading pacemaker site in the SAN itself rather than the change of the exit site. ${ }^{1718)}$ Our result supports the pacemaker hierarchy suggested by Boineau et al. ${ }^{1920)}$

\section{Mechanisms of rhythm generation of the subsidiary pacemaker}

Multiple time- and voltage-dependent ionic currents have been identified in cardiac pacemaker cells and these currents contribute to diastolic depolarization, including $\mathrm{I}_{\mathrm{f}}, \mathrm{I}_{\mathrm{Ca}-\mathrm{I}}, \mathrm{I}_{\mathrm{Ca}-\mathrm{T}}$, $\mathrm{I}_{\mathrm{ST}}$ and various types of delayed rectifier $\mathrm{K}$ currents. ${ }^{452) 21}$ The " $\mathrm{Ca}^{2+}$ clock" has recently been proposed as a complimentary mechanism of SAN automaticity. ${ }^{6-11)}$ The mechanism of heart rhythm generation by the SP has not been completely revealed. Using intracellular recordings, Rubenstein and Lipsius. ${ }^{22}$ suggested that multiple mechanisms participate in 
the SP automaticity. They included a cesium-sensitive component, a component mediated via the calcium released from the SR and possibly a direct contribution by the slow inward calcium current. However, the cells in different portions of the RA exhibit a range of electrophysiological and $\mathrm{Ca}^{2+}$ handling characteristics. ${ }^{23-26)}$ Moreover, because the leading pacemaker sites are shifting according to sympathetic stimulation, single cell recordings cannot reflect the exact cells from the leading pacemaking site.

Optical mapping of the intact RA to study the SAN function has the advantage that differential responses to $\beta$-adrenergic stimulation and other interventions can be characterized regionally within the leading pacemaker site and then compared to the RA. In this study, LDCAE was not observed at baseline and even during isoproterenol infusion in the SP model, while it was observed in the SAN during $\beta$-adrenergic stimulation. One possible explanation of this finding is that the $\mathrm{Ca}^{2+}$ clock lagged behind the voltage clock in regulating diastolic depolarization under basal conditions. Alternatively, because each pixel in an optical map contains information from multiple cells, the effects of spatial averaging might have pre-

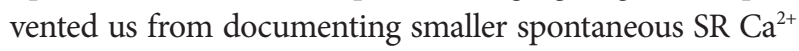
releases or $\mathrm{Ca}^{2+}$ releases from individual SAN cells. The importance of $\mathrm{SR} \mathrm{Ca}^{2+}$ release on heart rate acceleration during $\beta$-adrenergic stimulation is also supported by the finding that ryanodine and ryanodine plus thapsigargin decreased the heart rate during isoproterenol infusion.

\section{Interdependency of two clocks in the rhythm generation of the subsidiary pacemaker}

The interdependence and synergy between the two clocks is evident from the pharmacologic responses (Fig. 7). If the two clocks were independent with the faster clock driving the heart rate under a given condition, then blocking the slower clock should have no effect on heart rate, whereas blocking the faster clock should decrease the heart rate to that of the slower clock (which could be either markedly or only slightly slower than the faster clock). However, since both SR inhibitors and $\mathrm{I}_{\mathrm{f}}$ blockade slowed the heart rate under basal conditions, as well as this blunted the isoproterenol-induced increase in the heart rate, the hypothesis of independent clocks can be excluded. However, as the two clocks are interdependent, the relative potency of SR inhibition versus $\mathrm{I}_{\mathrm{f}}$ blockade on slowing the heart rate (Fig. 7) becomes very difficult to interpret since interdependency implies that inhibiting the SR $\mathrm{Ca}^{2+}$ release will affect the voltage clock as well as the $\mathrm{Ca}^{2+}$ clock, and vice versa. The interpretation is further complicated by the presence of ectopic foci outside the mapped region during SAN suppression.

\section{Study limitations}

In this study, the level of $\mathrm{Ca}_{\mathrm{i}}$ elevation at the subsidiary pa- cemaking site was too small to be detected by optical mapping. However, there is no doubt that the SR $\mathrm{Ca}^{2+}$ release contributes in the heart rate acceleration during $\beta$-adrenergic stimulation because the heart rate was reduced by ryanodine and a combined infusion of ryanodine and thapsigargin. Pharmacologic agents such as ryanodine, thapsigargin and $\mathrm{ZD}$ 7288 are not completely selective, and nonspecific effects cannot be excluded.

\section{Conclusion}

The block of spontaneous SR Ca ${ }^{2+}$ release or the funny current decreased the firing rate of the SP and it showed the concomitant suppression of heart rate acceleration by $\beta$-adrenergic stimulation. Our results support the conclusion that spontaneous $\mathrm{SR} \mathrm{Ca}^{2+}$ release acts synergistically with the activation of membrane ionic currents such as $\mathrm{I}_{\mathrm{f}}$, to accelerate the heart rate in the SP model during $\beta$-adrenergic stimulation.

\section{Acknowledgments}

This study was supported by funding from the Korean Circulation Society (7-2009-0545), a faculty research grant of Yonsei University College of Medicine (6-2009-0176, 6-2010-0059, 7-2009-0583), the Basic Science Research Program through the National Research Foundation of Korea as funded by the Ministry of Education, Science and Technology (20100021993) and a Korean Healthcare Technology Research and Development grant (number A085136).

\section{REFERENCES}

1) Adán V, Crown LA. Diagnosis and treatment of sick sinus syndrome. Am Fam Physician 2003;67:1725-32.

2) Randall WC, Talano J, Kaye MP, Euler D, Jones S, Brynjolfsson G. Cardiac pacemakers in absence of the SA node: responses to exercise and autonomic blockade. Am J Physiol 1978;234:H465-70.

3) Rozanski GJ, Lipsius SL, Randall WC. Functional characteristics of sinoatrial and subsidiary pacemaker activity in the canine right atrium. Circulation 1983;67:1378-87.

4) DiFrancesco D. Pacemaker mechanisms in cardiac tissue. Annu Rev Physiol 1993;55:455-72.

5) DiFrancesco D. The pacemaker current $(I(f))$ plays an important role in regulating SA node pacemaker activity. Cardiovasc Res 1995;30: 307-8.

6) Hata T, Noda T, Nishimura M, Watanabe Y. The role of Ca2+ release from sarcoplasmic reticulum in the regulation of sinoatrial node automaticity. Heart Vessels 1996;11:234-41.

7) Ju YK, Allen DG. Intracellular calcium and $\mathrm{Na}+-\mathrm{Ca} 2+$ exchange current in isolated toad pacemaker cells. J Physiol 1998;508:153-66.

8) Bogdanov KY, Vinogradova TM, Lakatta EG. Sinoatrial nodal cell ryanodine receptor and $\mathrm{Na}(+)-\mathrm{Ca}(2+)$ exchanger: molecular partners in pacemaker regulation. Circ Res 2001;88:1254-8.

9) Vinogradova TM, Bogdanov KY, Lakatta EG. Beta-adrenergic stimulation modulates ryanodine receptor $\mathrm{Ca}(2+)$ release during diastolic depolarization to accelerate pacemaker activity in rabbit sinoatrial nodal cells. Circ Res 2002;90:73-9.

10) Vinogradova TM, Zhou YY, Maltsev V, Lyashkov A, Stern M, Lakatta EG. Rhythmic ryanodine receptor Ca2+ releases during diastolic depolarization of sinoatrial pacemaker cells do not require membrane depolarization. Circ Res 2004;94:802-9.

11) Vinogradova TM, Lyashkov AE, Zhu W, et al. High basal protein kinase A-dependent phosphorylation drives rhythmic internal Ca2 + store oscillations and spontaneous beating of cardiac pacemaker cells. Circ Res 2006;98:505-14. 
12) Joung B, Tang L, Maruyama M, et al. Intracellular calcium dynamics and acceleration of sinus rhythm by beta-adrenergic stimulation. Circulation 2009; 119:788-96.

13) Joung B, Ogawa M, Lin SF, Chen PS. The calcium and voltage clocks in sinoatrial node automaticity. Korean Circ J 2009;39:217-22.

14) Joung B, Shinohara T, Zhang H, et al. Tachybradycardia in the isolated canine right atrium induced by chronic sympathetic stimulation and pacemaker current inhibition. Am J Physiol Heart Circ Physiol 2010; 299:H634-42.

15) A comparison of antiarrhythmic-drug therapy with implantable defibrillators in patients resuscitated from near-fatal ventricular arrhythmias: the Antiarrhythmics versus Implantable Defibrillators (AVID) Investigators. $N$ Engl J Med 1997;337:1576-83.

16) Joung BY, Koo BK, Xu ZZ, Kim IK, Lee MH, Kim US. The effects of obstacles on the dynamics of ventricular fibrillation. Korean Circ $J$ 2005;35:183-91.

17) Fedorov VV, Schuessler RB, Hemphill M, et al. Structural and functional evidence for discrete exit pathways that connect the canine sinoatrial node and atria. Circ Res 2009;104:915-23.

18) Efimov IR, Fedorov VV, Joung B, Lin SF. Mapping cardiac pacemaker circuits: methodological puzzles of the sinoatrial node optical mapping. Circ Res 2010;106:255-71.

19) Boineau JP, Schuessler RB, Mooney CR, et al. Multicentric origin of the atrial depolarization wave: the pacemaker complex: relation to dynamics of atrial conduction, $P$-wave changes and heart rate control.
Circulation 1978; 58:1036-48.

20) Boineau JP, Miller CB, Schuessler RB, et al. Activation sequence and potential distribution maps demonstrating multicentric atrial impulse origin in dogs. Circ Res 1984;54:332-47.

21) Dobrzynski H, Boyett MR, Anderson RH. New insights into pacemaker activity: promoting understanding of sick sinus syndrome. Circulation 2007; 115:1921-32.

22) Rubenstein DS, Lipsius SL. Mechanisms of automaticity in subsidiary pacemakers from cat right atrium. Circ Res 1989;64:648-57.

23) Verheijck EE, van Kempen MJ, Veereschild M, Lurvink J, Jongsma HJ, Bouman LN. Electrophysiological features of the mouse sinoatrial node in relation to connexin distribution. Cardiovasc Res 2001;52:4050 .

24) Lei M, Jones SA, Liu J, et al. Requirement of neuronal- and cardiactype sodium channels for murine sinoatrial node pacemaking. J Physiol 2004;559:835-48.

25) Lancaster MK, Jones SA, Harrison SM, Boyett MR. Intracellular $\mathrm{Ca} 2+$ and pacemaking within the rabbit sinoatrial node: heterogeneity of role and control. J Physiol 2004;556:481-94.

26) Tellez JO, Dobrzynski H, Greener ID, et al. Differential expression of ion channel transcripts in atrial muscle and sinoatrial node in rabbit. Circ Res 2006;99:1384-93.

27) Efimov IR, Nikolski VP, Salama G. Optical imaging of the heart. Circ Res 2004:95:21-33. 